combined weight of $2.7 \mathrm{~kg}$. They were both conscious, satisfactorily active with good intermittent cries. They were neither pale nor jaundiced. Their skins were joined from the sternum down to the hypogastrium. Twin 1 looked smaller and dehydrated. There was cyanosis on the left leg and right foot. There was also edema on the left foot. Her respiratory rate was 34 cycles per minute, the heart rate was $120 \mathrm{bpm}$, and the femoral pulse on that left leg was not palpable. First and second heart sounds were heard; there were no murmurs. The breath sounds were vesicular in both lungs fields. The Bowel sounds were present and normal. A rectal examination confirmed that she had patent anal orifices with good sphincteric tone. All other systems were grossly normal. Twin 2 was bigger and looked generally healthier than twin 1 . All her vital signs and clinical findings were essentially normal. The diagnosis of Thoraco-omphalopagous conjoint twins was then made.

Size 6 feeding tube was successfully passed into the stomach of each of the babies and gastric juices with bile were obtained from each of them. $10 \%$ Dextrose in $1 / 5$ normal saline was set up on each of them to run as calculated by their combined weight. Vitamin $\mathrm{K}$ injection was given to each intramuscularly. The babies were kept warm by wrapping with warm packs and blanket. It was decided to refer them to center that is conversant with management of conjoint twins. After three days at the referral hospital, the babies suddenly died one after the other. Aspiration of feeds was highly suspected, because there were no ante-mortem signs of distress.

Postmortem examination revealed that all the joining from the sternum to the hypogastrium was predominantly at the skin level. No organs were shared. The sternae, the ribs, the thoracic cavities and viscera were all separate. However, the heart of twin 1 had a single chamber from which emanated the aorta. The heart of twin 2 had the usual 4 chambers but they were enlarged. Other systems were essentially normal. Cause of death was then ascribed to Heart failure.

The exact incidence of conjoint twinning is unknown and figures are unreliable because not all cases reach the hospital; some are aborted while some are thrown away as monsters. The figure however is in the range of 1 in 14000 births in the non-caucasian. ${ }^{5}$

Although vaginal delivery for conjoint twins has been reported, ${ }^{1}$ when diagnosed in utero, the recommended mode of delivery is cesarean section not vaginal delivery, because of the attendant risks to both mother and twins. ${ }^{2,4}$ Undiagnosed conjoint twins may cause dystocia in labor leading to emergency operative delivery thereby endangering the survival of the twins. Surprisingly, there were none of such in this case. When diagnosis is made after birth, prompt transfer to a more ideal institution is a wise decision, as was done for these twins.

There is great need to improve the health care delivery system to make it available and accessible to all our pregnant women. Education of our women on the need for antenatal registration, regular antenatal clinic attendance and hospital delivery should be emphasized. This will make for early detection of such anomalies so that proper arrangement could be made for safe delivery and management of the conjoint babies.

\section{P. C. Ibekwe ${ }^{1}$ and C. E. O. Onuoha ${ }^{2}$}

${ }^{1}$ Department of Obstetrics and Gynaecology, Ebonyi State University Teaching Hospital, P. M. B .077, Abakaliki, Ebonyi State, Nigeria

${ }^{2}$ Department of Paediatric Surgery, Ebonyi State University Teaching Hospital, P. M. B .077, Abakaliki, Ebonyi State, Nigeria

\section{Reference}

1. Grower JI, Teste DW, Teich S. Dicephalic dipus dibrachius an unusual case of conjoint twins. J Pediatr Surg. 1996;31:1698-1700.

2. Owolabi AT, Oseni SBA, Sowande OA, et al. Dicephalus dibrachius dipus conjoined twin in a triplet pregnancy. Trop J Obstet Gynaecol. 2005;22:87-889.

3. Siegel I. Thoracopagous. Vaginal delivery without destructive operation. Med J Aust. 1950;97:40.

4. Green DJ. Vaginal delivery of conjoint. Med J Aust. 1981;2:356-360.

5. Nelson MM, Bhethay E, Beighton P. Excessive Siamese twinning. S Afr Med J. 1976;50:697-698.

\title{
Perception and Management of Guinea Worm DiSEASE IN INFECTED AND AT RISK NON- INFECTED Communities in Oyo State, Nigeria
}

Dracunculiasis or guinea worm disease caused by worm infestation continues to be a public health problem among rural communities in Africa, which depend upon unprotected water sources for drinking. 
Its health, social, educational and economic cost to the individual, the household and the community which is considerable and it's transmission cycle are well documented. ${ }^{1,2}$ Key intervention strategies to eradicate guinea worm are safe water supply, vector control using abate, health education and case management. Besides the worm itself and the stagnant water/copepods combination, the third element in the cycle of the disease is the human being. This is probably the key element, for without the people's cooperation and understanding none of the control strategies or intervention efforts will have much chance to succeed.

The aim of this study therefore is to find out knowledge, attitude and practises (KAP) in the management of guinea worm disease in infected and at-risk non-infected villages.

This study was carried out in12 villages in Akinyele Local Government Area (LGA) of Oyo State, Nigeria which lies between latitude $7^{\circ} 26^{\prime} 23^{\prime \prime} \mathrm{N}$ to $7^{\circ}$ $40^{\prime} 30^{/ /} \mathrm{N}$ and between longitude $3^{\circ} 47^{\prime} 4^{\prime /} \mathrm{E}$ to $4^{\circ} 05^{\prime}$ $00^{/ /} \mathrm{E}$.

Infected villages include these ones with their population at the time of study, Alagba (297),Oyeteju (45) and Olomitutu (215) while at-risk non-infected villages include Apapa (50houses), Alase (45houses), Ketepe (77), Deinlokun (25 houses), Aba Oso (56), Olorisaoko (55 houses), Alore (16 houses), Aroro (10 houses) and Ajibade (over 100 houses). Pretested and structured questionnaires were administered to all heads of households in infected and small noninfected villages while it was administered to every other house in bigger non-infected villages. The questions were translated into the language of the community, Yoruba. The questionnaire was used to record the demographic information of respondents. Source and treatment of drinking water, time of first infection, season, anatomical location, duration and severity of the infection were recorded. Effect of the disease on farming activities, information on the medication used and the knowledge of the disease were also recorded.

Two hundred and sixty(260) households were sampled. $35.4 \%$ households in infected villages and $64.6 \%$ households in non-infected villages. $63.1 \%$ males and $36.9 \%$ females were sampled. $80.8 \%$ were farmers. The number of respondents (75) that practice boiling and filtering of drinking water in infected villages is significantly higher than the number of respondents (32) that practice same treatment in non-infected villages $\left(X^{2}=95.5 ; P<.05\right)$ Some respondents use alum as a preventive measure against guinea worm disease. $46.7 \%$ of the respondents from infected areas and $48.8 \%$ from non-infected areas had been infected before, $29.6 \%$ had their first infection as a child and had been reinfected many times. Most (68.8\%) of the respondents were infected in the dry season. Most (91.2\%) had the guinea worm coming out of their legs (Figure 1). Almost all the respondents (96\%) had only one worm emerging at any one time. The period of disability in treated and untreated cases lasted from 1- 10 days to over a year. Table 1 shows symptoms perceived before bleb formation. $73.6 \%$ had their guinea worm ulcer healed within 1- 30 days. Most (81.6\%) use palm oil for treatment. Herbs used include the traditional drug (agbo) made from boiled medicinal leaves (Olugambe leaves - Ipomea spp). Most of the respondents infected before (76\%) could not farm at the time of infection and only $12 \%$ had alternative labor. Table 1 also shows that majority of the respondents from the infected villages (65.2\%) and $66.1 \%$ from non-infected villages were ignorant of the fact that the guinea worm infection is caused by drinking contaminated water. When respondents were further probed, $70.7 \%$ in infected villages and $76.8 \%$ in non - infected villages did not know guinea worm is transmitted in drinking water.

$81.2 \%$ of the respondents from all areas believed that all ages are equally susceptible to infection. There is no significant difference between the number of people that know susceptibility is due to the use of bad water in infected and non-infected areas $\left(X^{2}=0.26 ; P>.05\right) .84 .2 \%$ from all villages did not know if the disease is preventable or not. $64.4 \%$ said it could be treated using palm-oil. Majority of the respondents from all areas $(77.3 \%)$ claimed to be doing nothing to control the disease in their houses. Of significance are the $10.4 \%$ that claimed to treat their drinking water for control.

It is necessary to educate the villagers on the role of ponds as transmission sites, on the need to boil water and filter drinking water and the inability of the alum to kill the parasites intermediate hosts.. Educating villagers in all areas will help curb the menace of importation of the disease to at - risk non-infected areas where little or nothing is done about disease prevention.

This study shows that guinea worm infection does not confer any tangible protective immunity on the patients. In this LGA where rainfall rises to a peak of $1000 \mathrm{~mm}$ in the wet season, transmission is restricted to the tail end of the dry season. Patent guinea worm disease therefore reaches its peak in the following late dry season and early rainy season. Guinea worm came out mostly from the legs of those infected and most had only one worm emerging at any given time as found in studies by Kale. ${ }^{2}$ The older respondents recognized the prodromal signs of guinea worm infection. Use of palmoil, shea-butter and herbs for treatment of the disease in this study conforms to earlier studies. ${ }^{1}$

The long incubation period of the disease (9-12 months) makes it hard for people to visualize the direct connection between the water they drink today and the disease they suffer the following year. 
Table 1. Guinea worm infection in Heads of Households in Akinyele Local Government Area

\begin{tabular}{|c|c|c|c|}
\hline Symptoms perceived before bleb formation & Infected areas & Non infected & Total \\
\hline Rashes & $21(48.8 \%)$ & $51(62.2 \%)$ & $72(57.6 \%)$ \\
\hline Burning sensation at site of blister formation & $17(39.5 \%)$ & $28(34.1 \%)$ & 45 (36\%) \\
\hline Cold & $9(20.9 \%)$ & 13 (15.9\%) & $22(17.6 \%)$ \\
\hline Blurred vision & $1(2.3 \%)$ & - & $1(0.8 \%)$ \\
\hline Fever & $2(4.7 \%)$ & $2(2.4 \%)$ & $4(3.2 \%)$ \\
\hline Appearance of worm under skin & $2(4.7 \%)$ & - & $2(1.6 \%)$ \\
\hline $\mathrm{Dk} / \mathrm{none}$ & $7(16.3 \%)$ & $13(15.9 \%)$ & $20(16 \%)$ \\
\hline Cough & - & $1(1.2 \%)$ & $1(0.8 \%)$ \\
\hline Headache & - & $1(1.2 \%)$ & $1(0.8 \%)$ \\
\hline \multicolumn{4}{|l|}{$\begin{array}{l}\text { Time it took guinea worm ulcer to heal in } \\
\text { respondents }\end{array}$} \\
\hline $1-30 d$ & $33(76.7 \%)$ & 59 (72.0\%) & 92 (73.6\%) \\
\hline Months & $4(9.3 \%)$ & $7(8.5 \%)$ & $11(8.8 \%)$ \\
\hline Dk & $3(7.0 \%)$ & $11(13.4 \%)$ & $14(11.2 \%)$ \\
\hline No ulcer & $3(7.0 \%)$ & $5(6.1 \%)$ & $8(6.4 \%)$ \\
\hline \multicolumn{4}{|l|}{$\begin{array}{l}\text { Treatment applied to the guinea worm infection } \\
\text { by respondents }\end{array}$} \\
\hline Palm oil & 35 (81.4\%) & 67 (81.7\%) & $102(81.6 \%)$ \\
\hline Shea butter & $17(39.5 \%)$ & $6(7.3 \%)$ & $23(18.4 \%)$ \\
\hline Herbs & $6(14.0 \%)$ & $8(9.8 \%)$ & $14(11.2 \%)$ \\
\hline Hospital & $3(7.0 \%)$ & $8(9.8 \%)$ & $14(11.2 \%)$ \\
\hline \multicolumn{4}{|l|}{$\begin{array}{l}\text { Perception of the cause of the guinea worm } \\
\text { disease by respondents. }\end{array}$} \\
\hline Bad drinking water & $13(14.1 \%)$ & $18(10.7 \%)$ & $31(11.9 \%)$ \\
\hline Inherited & $12(13.0 \%)$ & $12(7.1 \%)$ & $24(9.2 \%)$ \\
\hline Others & $7(7.6 \%)$ & $30(17.9 \%)$ & $37(14.2 \%)$ \\
\hline Don't know & $60(65.2 \%)$ & $111(66.1 \%)$ & $171(65.8 \%)$ \\
\hline \multicolumn{4}{|l|}{$\begin{array}{l}\text { "do you know that guinea worm disease is } \\
\text { transmitted through drinking water?" }\end{array}$} \\
\hline Yes & $26(28.3 \%)$ & $34(20.2 \%)$ & $60(23.1 \%)$ \\
\hline No & $1(1.1 \%)$ & $5(3.0 \%)$ & $6(2.3 \%)$ \\
\hline Don't know & $65(70.7 \%)$ & $129(76.8 \%)$ & 194(74.6\%) \\
\hline \multicolumn{4}{|l|}{$\begin{array}{l}\text { "which people in the community are usually } \\
\text { susceptible to infection?" }\end{array}$} \\
\hline Any age & 77 (83.6\%) & 134 (79.8\%) & $211(81.2 \%)$ \\
\hline Both $15+$ male\& female & - & $1(0.6 \%)$ & $1(0.4 \%)$ \\
\hline Dk & $15(16.3 \%)$ & 33 (19.6\%) & $48(18.5 \%)$ \\
\hline \multicolumn{4}{|l|}{ Reasons for susceptibility } \\
\hline Bad water & $13(14.1 \%)$ & 20(11.9\%) & $33(12.7 \%)$ \\
\hline Inherited susceptibility & $40(43.5 \%)$ & $29(17.3 \%)$ & $69(26.5 \%)$ \\
\hline Don't know & $42(45.7 \%)$ & $120(71.4 \%)$ & $162(62.3 \%)$ \\
\hline \multicolumn{4}{|l|}{ "can guinea worm disease be prevented?" } \\
\hline Yes & $14(15.2 \%)$ & $24(14.3 \%)$ & $38(14.6 \%)$ \\
\hline No & $1(1.1 \%)$ & $2(1.2 \%)$ & $3(1.2 \%)$ \\
\hline Don't know & $77(83.7 \%)$ & $142(84.5 \%$ & $219(84.2 \%)$ \\
\hline \multicolumn{4}{|l|}{$\begin{array}{l}\text { Ways of preventing the disease (out of those that } \\
\text { said yes) }\end{array}$} \\
\hline Government action & $3(21.4 \%)$ & $1(4.2 \%)$ & $4(10.5 \%)$ \\
\hline Avoiding flood & - & $1(4.2 \%)$ & $1(2.6 \%)$ \\
\hline Good drinking water & $11(78.6 \%)$ & $15(62.5 \%)$ & $26(68.4 \%)$ \\
\hline Good food & $3(21.4 \%)$ & - & $3(7.9 \%)$ \\
\hline Cleanliness & $1(7.1 \%)$ & $6(25 \%)$ & $7(18.4 \%)$ \\
\hline Traditional medicine & - & $1(4.2 \%)$ & $1(2.6 \%)$ \\
\hline
\end{tabular}


Figure 1. Site of Guinea worm infection in Heads of Households in Akinyele Local Government Area

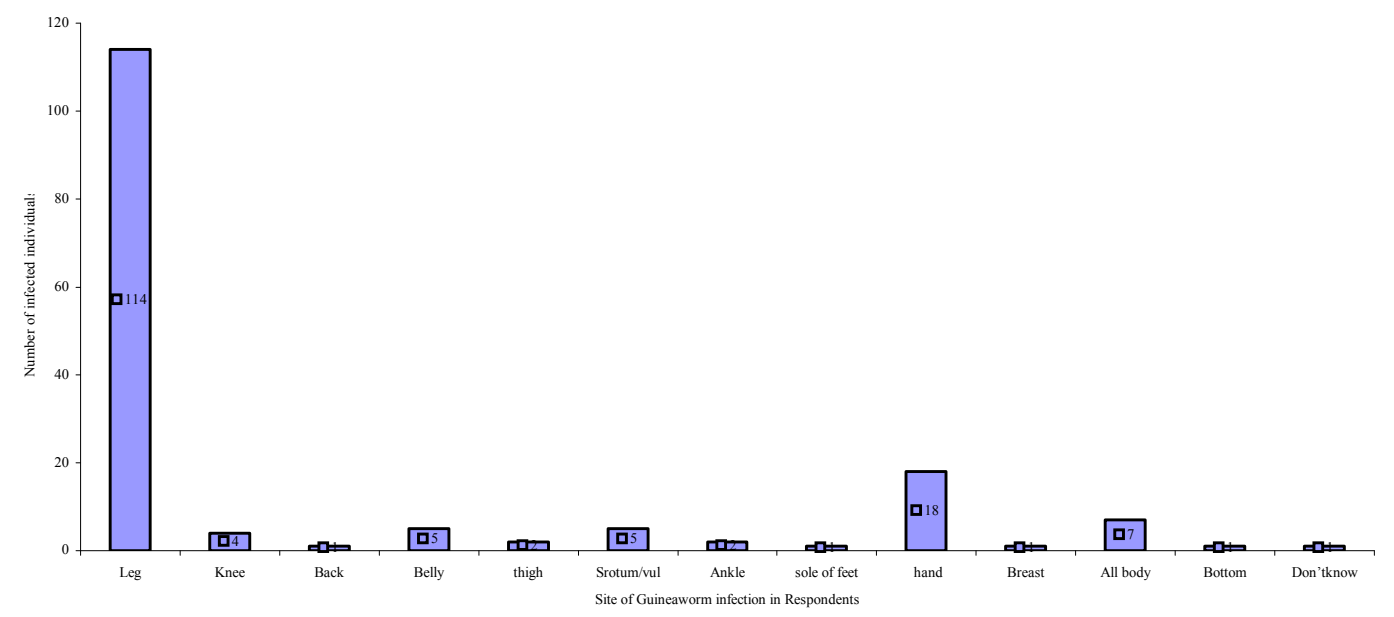

Most (74.6\%) of respondents interviewed did not know if the guinea worm is transmitted in drinking water or not which shows that water treatment was not done out of conviction.

Some of the respondents never infected before claimed to have movement of worms all over their bodies. Respondents believe infection is not from drinking water because some people in the infected villages had never been infected before although born and lived all their lives there and because they feel it is either in the body, blood or a family disease of those infected. Those that said it is from drinking water stated it must be from a common source.

When villagers' minds are not set on getting rid of the disease, it might be difficult to eradicate the disease completely in the country. The location of boreholes and wells is not possible in all areas because of small population and topography of some areas. It will therefore be advantageous if health education is made to cover infected and at-risk noninfected areas in order to speed up the eradication of the disease.

\section{Acknowledgments}

This work was partly supported by UNICEF Southwest Zonal Office, Nigeria.

\section{O. A. Morenikeji and A. B. Odaibo}

Department of Zoology, University of Ibadan, Nigeria E-mail: jumokemorenikeji@yahoo.co.uk

\section{References}

1. Belcher DW, Wurapa FK, Ward WB, Lourie IM. Guinea worm in southern Ghana: its epidemiology and impact on agricultural productivity. Am J Trop Med Hyg. 1975;24:243249.

2. Kale 0O. Clinico-epidemiological profile of guinea worm in Ibadan district of Nigeria. Am J Trop Med Hyg. 1977;26:208-214.

3. Brieger WR, Ramakrishna J, Adeniyi JD, Sridhar MKC, Kale OO. Guinea worm control case study: planning a multi-strategy approach. Soc Sci Med. 1991;32:1319-1326. 